\title{
Evaluation of a Crank-type Walking Cultivator for Upland Farming
}

\author{
Tae Hyeong Kwon ${ }^{1}$, Alireza Ashtiani-Araghi', Chungu Lee ${ }^{1}$, Tae Gyoung Kang ${ }^{3}$, \\ Byeong-Mo Lee ${ }^{4}$, Joong-Yong Rhee ${ }^{1,2} *$ \\ ${ }^{1}$ Dept. of Biosystems Engineering, Seoul National University, Seoul, 151-921, Republic of Korea \\ ${ }^{2}$ Research Institute for Agriculture and Life Sciences, Seoul National University, Seoul, 151-921, Republic of Korea \\ ${ }^{3}$ Dept. of Agricultural Engineering, National Academy of Agricultural Science, \\ Rural Development Administration. Suwon, Korea \\ ${ }^{4}$ Dept. Of Organic Agriculture, National Academy of Agricultural Science, Rural Development Administration, \\ Suwon, Gyeonggi, 441-707, Republic of Korea
}

Received: November $20^{\text {th }}, 2013$; Revised: January $25^{\text {th }}, 2013$; Accepted: February $19^{\text {th }}, 2014$

\section{Abstract}

Purpose: This research was conducted to evaluate feasibility of a crank-type walking cultivators for weeding in furrowed upland. Methods: A walking cultivator developed by RDA was selected and evaluated with its working speed (S), cultivation depth (CD) and weeding performance (WP). The evaluation was performed in upland field on July and August, 2012. Also kinematic analysis of the machine was performed to draw out design improvements. Results: $\mathrm{S}$ in flat, uphill and downhill were about $0.11 \mathrm{~m} \mathrm{~s}^{-1}, 0.11 \mathrm{~m} \mathrm{~s}^{-1}$, and $0.13 \mathrm{~m} \mathrm{~s}^{-1}$ respectively. It was found that $\mathrm{S}$ had a low relevance with user conditions. The CD was $35 \sim 40 \mathrm{~mm}$ which was satisfied with the RDA guide for weeding machine. A wide variation was observed in values of WP depending on the growth stages of weeds and field conditions. The cultivator showed low performance in eliminating the well-grown weeds. Kinematic simulation revealed that high forward speed caused a high ratio of un-weeded area. Conclusions: The weeding performance of the cultivator was satisfactory for weeds in early growth stage but it showed difficulties in handling on up-slope and in entering up-land. Specifically, the weight of the cultivator was judged as overweight for female workers. The crank-hoe type cultivator was judged as unsuitable for small walking type machine due to weight of the four-bar linkage system. Kinematic analysis revealed that the ratio of crank speed to the ground speed must be $850 \mathrm{rpm} \mathrm{s} \mathrm{m}^{-1}$ ( $255 \mathrm{rpm}$ based on $0.3 \mathrm{~m} \mathrm{~s}^{-1}$ ) or greater to avoid uncultivated area. Selection of forward speed is a decisive factor in designing the weeding cultivator.

Keywords: Organic farming, Performance evaluation, Upland field furrow cultivator, Walking cultivator, Weed control

\section{Introduction}

The negative perception of agricultural chemicals among food consumers gives preference and added-values to organic foods which are produced without the intervention of synthetic agricultural chemicals and fertilizers. In 1990s, government of Korea enacted the legislation, so-called "Environmentally-Friendly Agriculture Promotion Act” for further promotion of organic farming (Sohn,

\footnotetext{
*Comesponding author: Joong-Yong Rhee

Tel: +82-2-880-460; Fax: +82-2-885-8027

E-mail: jyr@snu.ac.kr
}

2002). Accordingly, production of the organic food has been increased from 68 thousand tons in 2005 to 123 thousand tons in 2011 (Ministry for Food, Agriculture, Forestry and Fisheries, 2012). Worldwide sale of organic products represents an annual growth by between $20 \%$ and 25\% (MA and Joachim, 2006).

However, there are several problems which limit and disturb the growth of the organic products market. Weed control has been known as the most dominant problem in organic farming. Physical weeding by cultivators can provide weed controlling without herbicides as well as save in labor time. Won et al. (2008) reported that the 
mechanical weed control could reduce $90 \%$ in the amount of working hours comparing with hand weed control. Cultivator suppresses the weeds through tillage practices. Conventional tillage including soil-inversion, can suppress high infestation of weeds (Gruber and Claupein, 2009; Nakamoto et al., 2006). Cultivator eliminates the weeds by damaging to weeds directly or burying weeds under soil surface. Burial and cutting at the soil surface are effective ways to control weeds (Bond and Grundy, 2001). Physical weeding is the most ordinary method even if various weeding methods in the organic farming such as physical, ecological and biological method are known (Ock and Pyon, 2011). Weeding can't be avoided because weeds prevails the crops in competition for nutrientwater use and result in considerable decreases of the crop yield.

Manual weeding by bare hands or simple hand tools are too hard to continue in the rural area because of aging of agricultural labor. Choe et al. (2012) reported that the ratio of the elderly was $31.8 \%$ on 2010 , contrast of $11.3 \%$ in urban area in rural area. The female workers correspond $52 \%$ of the total farm labor (Kang, 2011). To make matters worse, large portion of upland are small scale, located on slope and managed by making ridge and furrows in Korea.

A small weeding machine which can be operated by the female and the old is necessary to continue the organic farming. For aged and feminized rural area, convenient weeding method is needed. Many researches have been performed about mechanical weed control in South Korea some of which were the attempts done to evaluate weeding by cultivators (Lee et al., 2007; Kim et al., 2006; Kim et al., 2007). However, most of these researches were performed for rice paddy and it is difficult to apply those results for upland farming due to the following reasons: firstly agricultural machinery cannot easily enter and work in upland fields with narrow furrows, Secondly there are various kinds of crops with different cultivation methods at each upland field and different width of furrows.

This study was initiated to develop a small weeding machine which could be operated by farmers regardless of gender for the organic farms. Rural Development Administration (RDA) developed two prototype weeding machines in 2011. In this report, field evaluation of the prototype which had cranked hoes was accomplished and kinematic analysis on the weeding mechanism was summarized. Based on the field test and theoretical consideration, some design improvements were suggested.

\section{Materials and Methods}

\section{The prototype weeding machines}

RDA developed small sized walking type power weeding machines with new weeding mechanism for upland organic farming as shown in Figure 1. The left one had two vertical shafts on which a pair of rotating blades was attached. The right one had three cranked hoes. The right one was selected as a test weeding machine because it achieved better evaluation score as a possible small powered weeding machine from farmers who attended on the demonstration \& evaluation meeting. The left one showed a serious problem of entanglement of weeds around the blades.
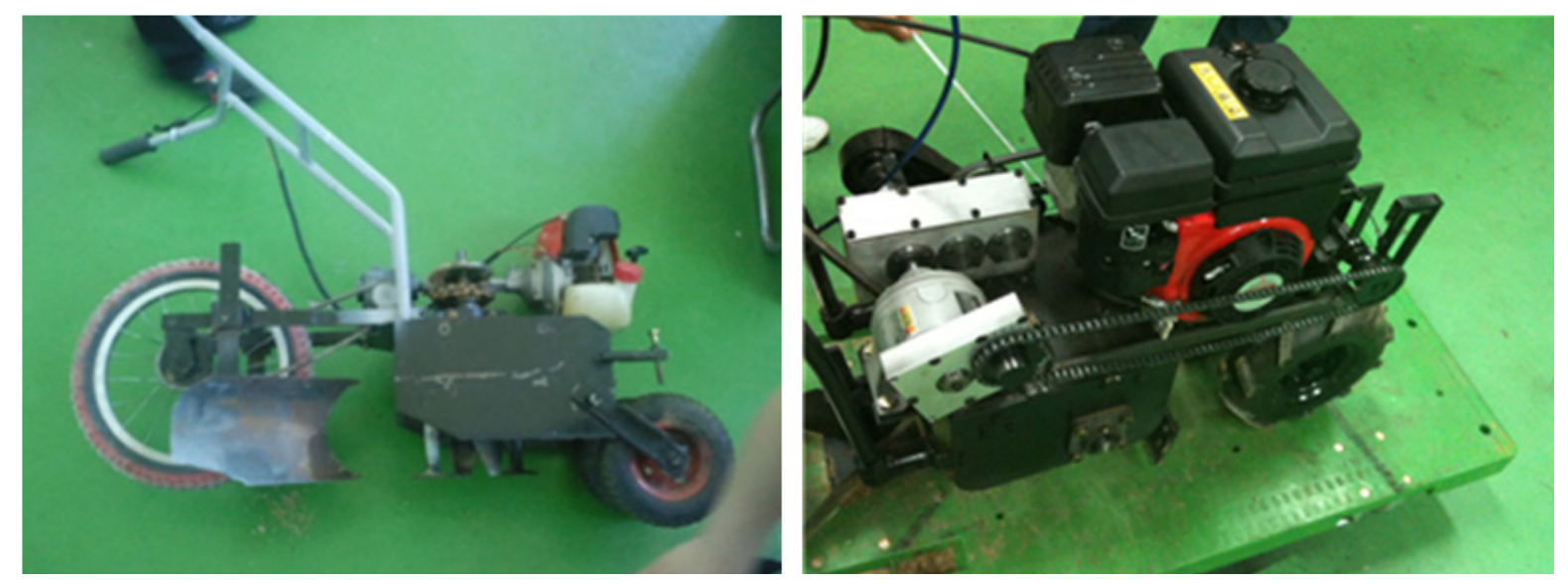

Figure 1. Prototype weeders; vertical rotating shaft type (left) and crank-hoe type (right). 


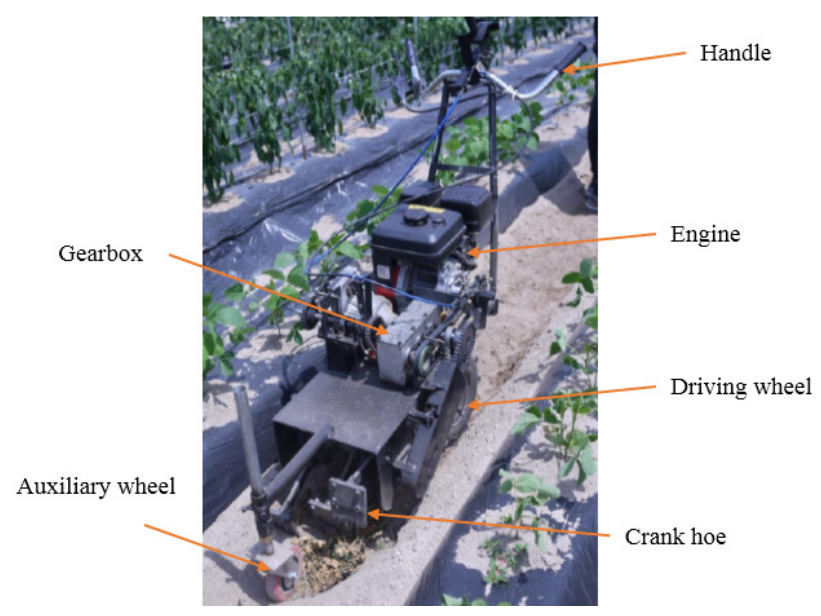

Figure 2. Appearance of the test cultivator.

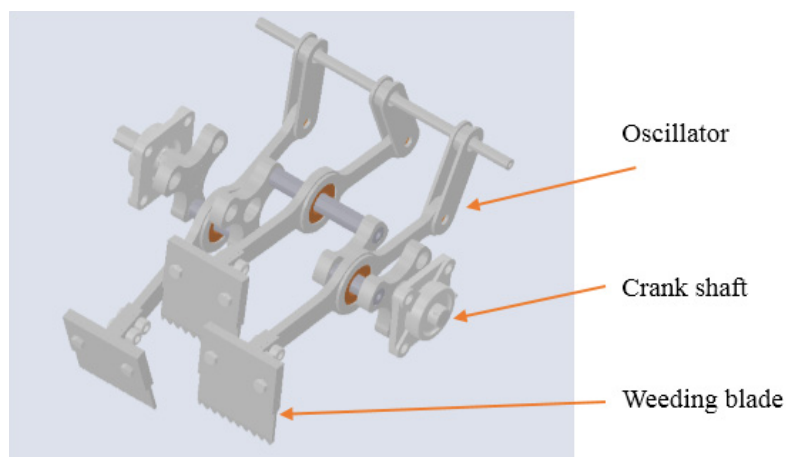

Figure 3. Schematic view of rotary shaft and other assemblies.

\section{Test weeding machine, crank-type walking cultivator}

The test weeding machine shown in Figure 2 was designed to work within furrows. It was equipped with a pairs of wheels for convenience of operators such as women and old farmers in steering and handling the machine. The weeding hoes were driven by the four-bar mechanism which mimicked the manual weeding as shown in Figure 3. This mechanism had been used for cultivating upland instead of rotary cultivators, so called 'rotavator'. This cultivators had been known to provide optimum soil breakage for crops while the rotavator break soil into excessively fine particles. Three hoes were placed in the weeding width and operated sequentially to avoid weeding power peak by positioning the crank shafts with $120^{\circ}$ interval. This machine was designed to provide $1-5 \mathrm{~cm}$ of weeding depth by adjusting the attaching points of blades to the four-bar mechanism and the relative position of the support wheel. It was equipped with a $3 \mathrm{~kW}$ gasoline engine, a gearbox with 1:30 of reduction ratio and a gear box for changing rotational

\begin{tabular}{|c|c|}
\hline Parameter & Contents \\
\hline Working type & Self-propelled (Walking) Crank-type \\
\hline General dimension & $900 \times 650 \times 370 \mathrm{~mm}$ \\
\hline Weeding width & $300 \mathrm{~mm}$ \\
\hline Weeding depth & Over $30 \mathrm{~mm}$ \\
\hline Engine model & Mitsubishi GB I30 (3 kW at $1800 \mathrm{rpm})$ \\
\hline Reduction ratio & $1: 30$ \\
\hline Total weight & $70 \mathrm{~kg}$ \\
\hline
\end{tabular}

direction. A clutch lever was installed on the handle to control power to the driving wheels and the weeding mechanism using a belt clutch mechanism. The general specifications of the test machine were shown in Table 1.

\section{Feasibility study}

The field test was accomplished in a soybean field in which the ridge was covered with plastic film. The fields were located in Bongwha-gun, Kyoungsangbook-do Korea; Uiwang-si, Gyeonggi-do Korea; Hwacheon-gun, Gangwon-do Korea. The height of the ridge was $15 \sim 17 \mathrm{~cm}$, and the width of furrow was $35 \sim 45 \mathrm{~cm}$. Three evaluation criteria were selected in this study. The reasons of choosing such criteria along with the evaluation methods are briefly discussed below.

\section{Field capacity (FC) and working speed (S)}

Field capacity of agricultural machinery is a complex indicator which tells machine's performance and skill of an operator (Chung and Kim, 1997). Field capacity (FC) is determined with working width (W), working speed (S) and field efficiency (FE) as shown in Equation (1). The field efficiency is related to skills of turning the machine and working without interruption. It is the ratio of actual field capacity or effective field capacity to the theoretical field capacity which assumes no time loss in working, in other words no turning and no time loss for adjustment.

$$
F C\left(\frac{h a}{h r}\right)=\frac{1}{10} \times F E(\text { decimal }) \times S\left(\frac{k m}{h r}\right) \times W(m)
$$

Because the official field efficiency of the test cultivator was not known yet, field capacity could not evaluate. In the field test, $S$ was measured instead of field efficiency in various condition; flat, uphill (10 15 degree of inclination) and downhill (10 15 degree of inclination) condition. The test machine was operated by several users. The $S$ 
was calculated by measuring the weeding time for $20 \mathrm{~m}$ long furrow using a stopwatch.

\section{Cultivation depth in situ}

Cultivating with tillers is known as an effective weed control method (Gruber and Claupein, 2009). Bond and Grundy (2001) reported that cultivation depth of $1 \mathrm{~cm}$ was common for weed control but it might be varied depending on the weed size. RDA made a guide for weeding machine that required cultivation depth (CD) of weeding machines should be over 3 m (RDA, 2008). In this study, cultivation depth was judged by the RDA guideline. The evaluated walking cultivator was "down-cut" type in which crank-hoe rotates to the same direction of wheels and throws the tilled soil in backward direction. The CD was measured by a steel ruler after running the crank hoe in stationary condition.

\section{Weeding performance in situ}

The weeding performance (WP) is the major evaluation criterion of the walking cultivator. In previous researches, the weeding performance was assessed by various methods such as counting number of weed plants (Roh and Pyon, 2004; Hwang et al., 2007; Kim et al., 2011), measuring dry matter (DM) (An et al., 2008; Lim et al., 2009; Ahn et al., 2010), reoccurrence ratio (Kim et al., 2008) etc.. RDA suggested to evaluate the WP by counting the number of weeds based on Equation (2) (RDA, 2008)

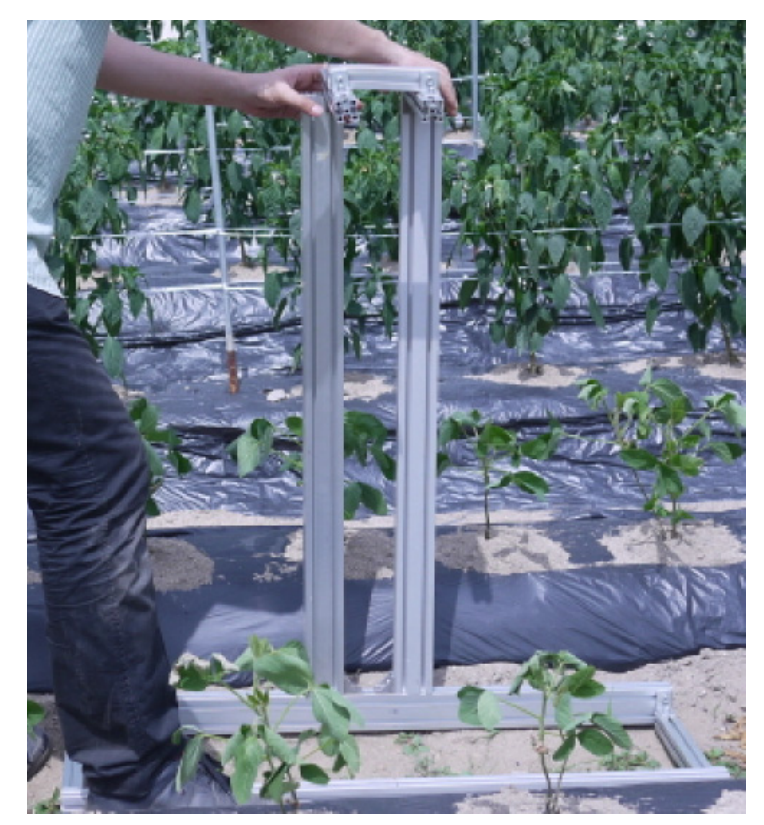

Figure 4. Installation of aluminum profile-made marker.

$$
W P(\%)=\left(1-\frac{W_{b}}{W_{a}}\right) \times 100
$$

where, $W_{b}$ : number of weeds after cultivator operation $W_{a}$ : number of weeds before cultivator operation

However, it is expected that the method of counting the number of weeds $(\mathrm{CN})$ is not capable to reflect the weed size. Therefore, DM of weeds was also involved with above methods in this study. Field test was repeated 11 times in two upland fields. A marker that could show the experimental port was developed by aluminum profile (Figure 4) while each experimental port was $90 \times 30 \mathrm{~cm}$. The marker was installed on the experimental port. After cultivation, the weeds were classified and collected based on "weeded" or "not weeded". Results from different methods were compared and the WP was determined by averaging the obtained values.

\section{Kinematic analysis of experimental cultivator}

Kinematic analysis was performed to find out some improvement points that could not be found during in-situ testing such as effective weeding depth and ratio of un-weeded area of the experimental cultivator. A computer simulation model using Recurdyn V7R5 MBD (FunctionBay Inc., Korea) multi-body dynamic simulation software was developed to analyze the kinematic behavior of the power cultivator. The simulation program has been effectively used as a reliable simulation tool for kinematics and dynamic evaluation in many researches (Wang et al., 2011; Xie et al., 2011; Huang et al., 2012).

Dimensions of the four bar linkage mechanism are given in Figure 6 which described the side view of the mechanism when the height of rear support wheel is set as $264 \mathrm{~mm}$.

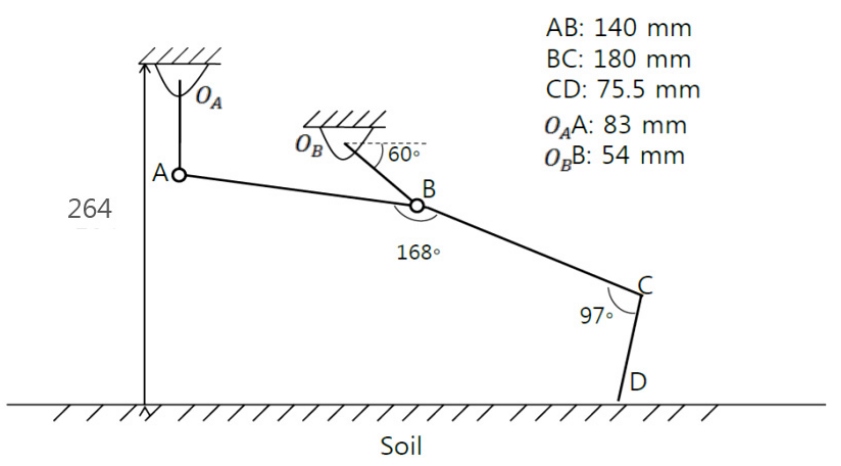

Figure 5. Dimensions of the weeding four bar linkage mechanism. 
A computer simulation model was developed based on dimensions and selected $\mathrm{S}$ of machine. The reference model considered a stationary operation in which no forward speed was assumed. The trace of blade tip point within the body soil has been obtained. Various hoeing paths were simulated by changing two operational parameters as shown in Table 2. Total 6 hoeing paths were achieved. The rotary speed of the weeding mechanism was kept constant at $60 \mathrm{rpm}$. Using the path traces, the effective cultivation depth and ratio of un-weeded area were evaluated. The effective cultivation depth is considered as an important performance criterion in RDA guideline (RDA, 2008). The ratio of un-weeded area was defined as the ratio of un-weeded distance to weeding pitch during one cycle.

The ratio of rotating speed to running speed is an important factor which influences the machine "weeding pitch". Weeding pitch of machine can be defined as the interval between two consecutive weeding actions. To ensure better weeding performance, a certain value of overlap is desired between successive blade actions on the soil. Applying different combinations of rotary and linear speeds give a minimum speed ratio for proper weeding operations.

To reduce the hoeing force, the weeding hoe involves a certain thickness and a specific shape for more strength. The cultivator was equipped with hoeing blades $10 \mathrm{~cm}$ wide, $5 \mathrm{~mm}$ thick, $1 \mathrm{~cm}$ deep for teeth and 45 for bevel angle on Figure 3). The angle made by blade length and the trace made by the hoe tip when simulated with forward velocity were considered as important engineering data which can affect the hoeing force. If the bevel angle of the blade is larger than the angle, the inclined surface may contact and pressurize the cut soil surface. This angle can be considered as the maximum allowed bevel angle of the hoeing blade tip in which the soil resistance force against the blade motion and energy for weeding operation diminishes.

\section{Results and Discussion}

\section{Evaluation of $S$ in situ}

The maximum theoretical speed of walking cultivator is $0.104 \mathrm{~m} \mathrm{~s}^{-1}$ and the maximum rotary speed of cultivator engine (GB130, Mitsubishi, Japan) is $1,800 \mathrm{rpm}$. The reduction ratio is $1 / 270$ and wheel diameter is $300 \mathrm{~mm}$. However, the $\mathrm{S}$ of designed cultivator was about $0.11 \mathrm{~m}$ $\mathrm{s}^{-1}$ in this research (Table 3 ). It was considered that actual $\mathrm{S}$ which is higher than maximum theoretical speed was caused by down-cut mechanism. The walking cultivator could gain extra velocity as a result of the interaction between crank-hoes and soil body. This result corroborates the results of a research done by Lee et al. (2003). Every replication had similar results which mainly originated from the rotation of powered wheels. Because of powered wheels, the $S$ was not influenced by field slope (Table 4). The $S$ was $0.11 \mathrm{~m} \mathrm{~s}^{-1}$ in uphill operation which was close to the walking speed on flatland operation. On the other hand, the $\mathrm{S}$ on downhill operation was $0.13 \mathrm{~m} \mathrm{~s}^{-1}$ which was due to slippage effect $(\mathrm{p}<0.05)$. Sliding down due to heavy weight of the walking cultivator was observed during downhill operation (Figure 6). Its heavy weight could be disadvantage of this cultivator because of difficult

Table 2. Variable parameters and their range for simulation

\begin{tabular}{cccc} 
Operation parameter & Number of simulated items & Increment step & Values for simulation \\
Working velocity & 2 & $0.1 \mathrm{~m} / \mathrm{s}$ & $0.2-0.3 \mathrm{~m} / \mathrm{s}$ \\
\hline Length of hoeing blade & 3 & $10 \mathrm{~mm}$ & $0-20 \mathrm{~mm}$ \\
\hline
\end{tabular}

Table 3. Working speed (S) on flatland

\begin{tabular}{ccccccccccc} 
Parameter & Rep.1 & Rep.2 & Rep.3 & Rep.4 & Rep.5 & Rep.6 & Rep.7 & Rep.8 & Rep.9 & Rep.10 \\
S $\left(\mathrm{m} \mathrm{s}^{-1}\right)$ & 0.11 & 0.12 & 0.10 & 0.10 & 0.10 & 0.11 & 0.11 & 0.12 & 0.12 & 0.11 \\
\hline
\end{tabular}

Table 4. Working speed (S) in uphill and downhill operations

\begin{tabular}{cccc} 
Parameter & Rep.1 & Rep.2 & Rep.3 \\
$\mathrm{S}$ in uphill $\left(\mathrm{m} \mathrm{s}^{-1}\right)$ & 0.11 & 0.11 & 0.11 \\
$\mathrm{~S}$ in downhill $\left(\mathrm{m} \mathrm{s}^{-1}\right)$ & 0.12 & 0.13 & 0.13 \\
\hline
\end{tabular}




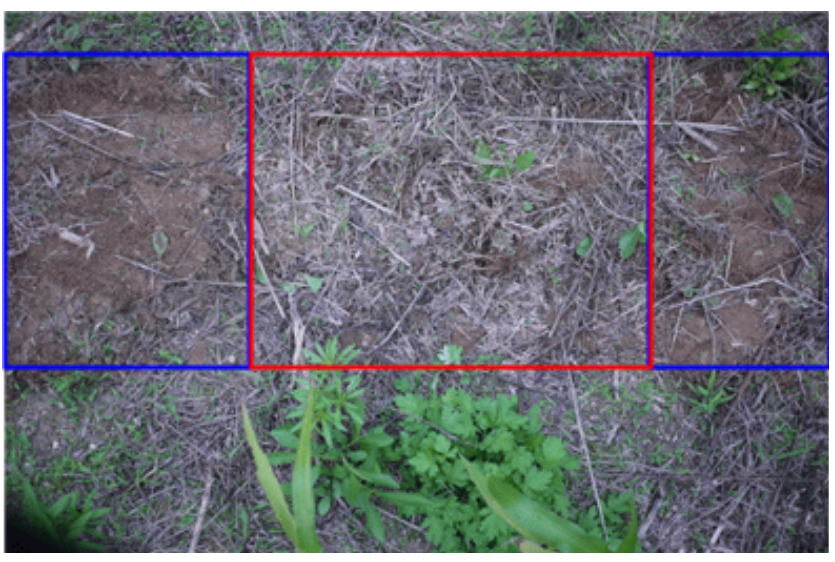

Figure 6. The gap of working area (center square) by cultivator's slippage.

operation. The experiment considering different properties such as age and gender of machine operators was performed and results are shown below (Table 5). According to the results, general condition of the operator, especially the gender, had a negligible effect on S. This is mostly caused by operation of drive wheels which provides a cultivator with less required efforts for the operation.

The $S$ could be increased by adjusting the reduction ratio but the fast $\mathrm{S}$ could lead to a lower WP in up-cut type cultivator. Therefore, the $S$ was adequate for considered WP.

\section{Evaluation of CD in situ}

The observed CD was $35 \sim 40 \mathrm{~mm}$ based on RDA suggestion and it was expected to be suitable for weed control. This range of $\mathrm{CD}$ values could be effective to eliminate the weeds grown above soil horizon but it is widely known that tillage could promote germination of dormant weed seeds. However, the seed germination by swallow tillage could not be analyzed because the reoccur ratio was not considered in this study.

\section{Evaluation of WP in situ}

Based on the method, counting number of weeds, average and standard deviation of the weeding ratio were $60.3 \%$ and $18.6 \%$, respectively (Table 6). In DM method, average of weeding ratio was $43.1 \%$ while relevant standard deviation was $17.5 \%$. It was observed both methods show different results from each other $(\mathrm{p}<0.001)$. It was observed that these results were caused by relatively well-grown weeds. Well-grown weeds had thick stems and deep roots and walking cultivator was technically deficient and incapable to eliminate well-grown weeds. Site (a)-2 had relatively well-grown weeds compared with Site (b) (Figure 7). Thus, the weeding ratio in Site (a)-2 was lower than Site (b).

Well-grown weeds control or repress strongly the growth of crops in compare with small young weeds. This

Table 5. Working speed (S) by different operator

\begin{tabular}{|cccccc|}
\hline Parameter & Operator 1 & Operator 2 & Operator 3 & Operator 4 \\
\hline Age & 58 & 22 & 28 & 24 \\
\hline Stature $(\mathrm{cm})$ & 165 & 155 & 174 & 172 \\
\hline Weight $(\mathrm{kg})$ & 65 & 45 & female & Male & 57 \\
\hline Gender & male & 0.13 & 0.12 & male \\
\hline $\mathrm{S}\left(\mathrm{m} \mathrm{s}^{-1}\right)$ & 0.14 & & & 0.13
\end{tabular}

Table 6. Result of weeding ratio

\begin{tabular}{|c|c|c|c|c|c|c|c|}
\hline \multirow{2}{*}{$\begin{array}{c}\text { Site }^{a)} \\
\text { Site (a)-1 }\end{array}$} & \multirow{2}{*}{$\begin{array}{c}\text { Method }^{\mathrm{b})} \\
\mathrm{CN}\end{array}$} & \multicolumn{6}{|c|}{ Weeding ratio (\%) } \\
\hline & & 60.9 & 37.5 & 70.4 & 66.7 & 54.5 & 60.0 \\
\hline & DM & 32.6 & 71.8 & 27.3 & 58.8 & 54.7 & 29.0 \\
\hline \multirow[t]{2}{*}{ Site (a)-2 } & $\mathrm{CN}$ & 36.4 & 33.3 & & & & \\
\hline & DM & 35.0 & 11.7 & & & & \\
\hline \multirow[t]{2}{*}{ Site (b) } & $\mathrm{CN}$ & 71.4 & 85.7 & 86.4 & & & \\
\hline & DM & 55.9 & 52.0 & 45.0 & & & \\
\hline
\end{tabular}

a) Site (a) is upland field in Bonghwa-gun, Gyeongsangbuk-do, Site (b) is in Uiwang-si Gyeonggi-do. Well-grown weeds were prevalent in Site (a)-2.

b) $\mathrm{CN}$ is based on counting number of weed method and DM is based on dry matter. 

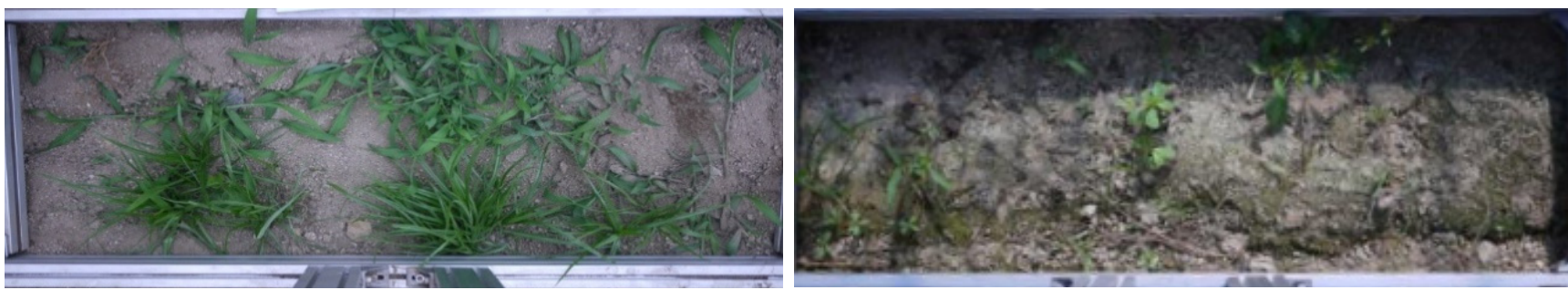

Figure 7. Different weed growth status in Site 1-2 (left) and Site 2 (right).

result shows the significance of tillage operation before the weeds can grow well as an effective factor in the weed control. Before the seeding, a tillage operation resulting in soil inversion could be effective in weed control. After seeding, the small scale cultivators for operating in furrows could be effective to eradicate young weeds. After that, new germinated weeds will have lower competition with grown crops. Likewise, use of proper time and repetition are also among the important factors to implement weed control by a cultivator as stated by Lee et al. (2010) and Lim et al. (2002). Therefore, in order to have a better use of the walking cultivator, an instruction about proper using dates is needed for organic farmers.

\section{Results of the kinematics analysis}

The simulation was performed for number of values in different parameters. Table 7 shows the obtained results of the simulation. As can be observed from Table 7, a longer hoeing blade remarkably increases the cultivation depth. However, the ratio of un-weeded area is so high for all trials. At a constant rotary speed, a decrease in forward speed improves the weeding efficiency since the ratio of un-weeded area is partially reduced.

High forward speed leads to a high un-weeding area. At this condition, the blade follows a "spot impact on the surface" behavior, a motion pattern which is more suitable for rice transplanting machines (Figure 8).

Table 7. Effects operation parameters on machine performance at $60 \mathrm{rpm}$

\begin{tabular}{|c|c|c|c|c|c|}
\hline \multicolumn{2}{|c|}{ Simulation condition } & \multicolumn{4}{|c|}{ Evaluation index } \\
\hline $\begin{array}{l}\text { Running speed } \\
\qquad\left(\mathrm{m} \mathrm{s}^{-1}\right)\end{array}$ & Length of blade (mm) & $\begin{array}{l}\text { Cultivation depth } \\
\qquad(\mathrm{mm})\end{array}$ & Weeding pitch $(\mathrm{mm})$ & $\begin{array}{c}\text { Ratio of un-weeded } \\
\text { area }(\%)\end{array}$ & $\begin{array}{c}\text { Maximum bevel angle } \\
\text { (deg) }\end{array}$ \\
\hline \multirow{3}{*}{0.2} & 75.5 & 25.3 & 201 & 77 & 36.7 \\
\hline & 85.5 & 34.2 & 200 & 74 & 39 \\
\hline & 95.5 & 43.2 & 200 & 73 & 41.3 \\
\hline \multirow{3}{*}{0.3} & 75.5 & 25.3 & 300 & 94 & 50 \\
\hline & 85.5 & 34.2 & 299 & 93.5 & 51.9 \\
\hline & 95.5 & 43.2 & 299.5 & 94 & 53.2 \\
\hline
\end{tabular}
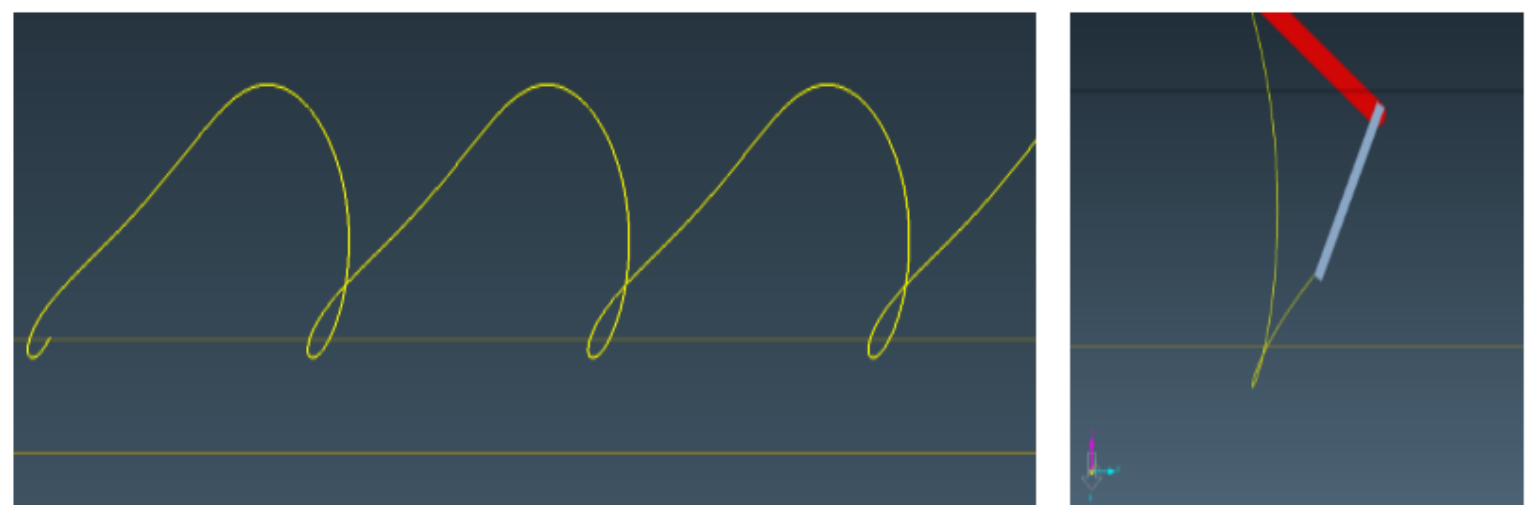

Figure 8. Path trace of hoeing blade with forward speed $0.3 \mathrm{~m} \mathrm{~s}^{-1}$ (left), $0.4 \mathrm{~m} \mathrm{~s}^{-1}$ (right). 


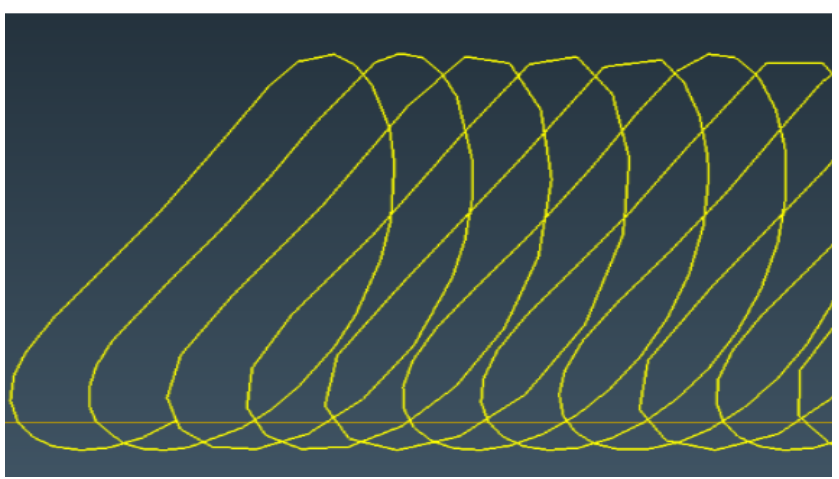

Figure 9. Weeding overlap in speed ratio of 1500.

Table 8. Simulation results for different speed ratios

\begin{tabular}{ccccc}
$\begin{array}{c}\text { Speed } \\
\text { ratio }^{\text {a) }}\end{array}$ & $\begin{array}{c}\text { Maximum } \\
\text { depth }(\mathrm{mm})\end{array}$ & $\begin{array}{c}\text { Maximum depth } \\
\text { in overlapped } \\
\text { part }(\mathrm{mm})\end{array}$ & $\begin{array}{c}\text { Depth ratio in } \\
\text { overlapped part } \\
\text { to maximum }(\%)\end{array}$ & $\begin{array}{c}\text { Overlap } \\
(\%)\end{array}$ \\
\hline 1000 & 16.6 & 5 & 30 & 6 \\
1200 & 16.6 & 9.5 & 57 & 12 \\
1500 & 16.6 & 12.4 & 75 & 20 \\
\hline
\end{tabular}

a) Speed ratio $=$ rotary speed $(\mathrm{rpm}) /$ forward speed $\left(\mathrm{m} \mathrm{s}^{-1}\right)$

b) Ratio of overlapped length to the length of cultivated per one cycle

Simulation also showed a speed ratio of $850 \mathrm{rpm} \mathrm{s} \mathrm{m}^{-1}$ was the minimum ratio in which a weeding overlap is started. This means that in the test machine, a rotational speed of $255 \mathrm{rpm}$ or higher is needed for $0.3 \mathrm{~m} \mathrm{~s}^{-1}$ forward speed to achieve the weeding overlap. Figure 9 shows simulation results at $1,500 \mathrm{rpm} \mathrm{s} \mathrm{m}^{-1}$ of speed ratio. In this figure, $20 \%$ of overlapping in the weeding is achieved. To secure the weeding effect, appropriate overlapping is necessary. In this simulation, the ratio of weeding depth at the overlapped position to maximum weeding depth is estimated to be $75 \%$. Table 8 shows the effect of speed ratio in the output of the weeding operation. Higher speed ratios boost the overlapping effect by an increase in overlapped lengths and depths which will result in well pulverized soil body and weeding effect such as uprooting and burying the damaged weeds. The maximum bevel angle for the hoeing blade increases for longer blades.

\section{Design improvements from the test and simulation}

The evaluation test revealed some design improvement points. One is the he weight of the cultivator. The weight of $70 \mathrm{~kg}$ was too heavy for women and old age to use it in field even if it equipped the drive wheels and support wheel which reduce handling difficulties, particularly in ascent movement. The weeding with a four-bar mechanism requires two gear boxes and several horizontal axes for cranks and oscillators including the drive wheels. The power train for this cultivator was judged too complicated compared to the simple cultivators. The weeding mechanism must be replaced with a rotary cultivator types to make a handy cultivator for women and old age. The other was the selection of the weeding speed. According to the kinematic simulation, when the $\mathrm{S}$ was $0.4 \mathrm{~m} \mathrm{~s}^{-1}$, the path trace of hoe tip collided at a spot. In the other aspect, the crank-type cultivator had contradiction between $\mathrm{S}$ and WP. To make WP high, $\mathrm{S}$ must be reduced. When $\mathrm{S}$ is over $0.4 \mathrm{~m} \mathrm{~s}^{-1}$, this cultivator cannot play a role as a weeder. In practical test, $S$ of the cultivator were $0.1 \mathrm{~m} \mathrm{~s}^{-1}$, nevertheless WP were about $60 \%$. Two factors could not satisfy the standard of RDA that are $0.25 \mathrm{~m} \mathrm{~s}^{-1}, 80 \%$, respectively. Therefore Selection of forward speed is a decisive factor in designing the weeding cultivator.

\section{Conclusions}

RDA developed two prototype weeding machines in 2011 to solve labor shortage in weeding for organic farms. In this paper, feasibility of the crank hoe type cultivator among the two was studied in field condition. Also the weeding mechanism was analyzed kinematically to find out improvement points.

The $\mathrm{S}$ of the test machine in flat, uphill and downhill condition were about $0.11 \mathrm{~ms}^{-1}, 0.11 \mathrm{~ms}^{-1}$ and $0.13 \mathrm{~m} \mathrm{~s}^{-1}$ respectively. This mean that the gravity affected the $S$ and the drive wheel power is sufficient to overcome the gravity in uphill condition. The test cultivator could be used easily regardless of gender or other conditions of the operators. The cultivating depth of the cultivator was $35 \sim 40 \mathrm{~mm}$, sufficiently large to control weeds effectively and satisfied the RDA guide for weeding machine. The weeding performance was about $60 \%$. Also the test cultivator showed low weeding performance when weeds were well-grown. However it showed difficulties in entering the furrows and turning at the field edge. The power train of the crank-type cultivator took most weight of the machine. In order to make a cultivator for female or old age, the test machine was judged as inappropriate.

The kinematic analysis showed that a remarkable portion of the blade travel time is spent out of the soil 
body which is the wasted part of a weeding cycle. In order to increase the interaction time between soil and weeding blade, the current generated path of the weeding blade needs to be improved by changing the position of the fixed link and dimensions of the moving links. An appropriate speed ratio between rotational speed of the rotary part and the linear speeds of machine improves the weeding quality as well. Kinematic analysis revealed that the ratio of crank speed to the ground speed must be $850 \mathrm{rpm} \mathrm{m}^{1} \mathrm{~s}$ or greater to avoid uncultivated area.

\section{Acknowledgement}

This study was supported by "Cooperative Research Program for Agriculture Science \& Technology Development (Project No. PJ008257)" Rural Development Administration, Republic of Korea. Also, the authors would like to thank Chang-wan Kim, Hye-won Jung and Hye-bin Yu who were undergraduate student of Biosystems Engineering, Seoul National University for their cooperation in this study.

\section{References}

Ahn, S. H., S. Kim, I. B. Im, Y. H. Moon, Y. L. Cha, S. T. Bark, B. C. Koo and S. J. Suh. 2010. Weeding effect of using soybean cake and cultivating weeder together in rice bran farming. Korean Journal of Weed Science 30(3): 266-271 (In Korean, with English abstract).

An, S. H., S. B. Lee and C. H. Yoo. 2008. Effects of soybean meal and mixture of soybean meal and rice bran on weed control and rice growth in the machine transplanting ride paddy fieldy. Korean Journal of Weed Science 28(3):236-241 (In Korean, with English abstract).

Bond, W and A. C. Grundy. 2001. Non-chemical weed management in organic farming system. Weed Research 41(5):383-405.

Choi, M. K. 2012. An analysis for the changing trends of residential environment based on the change of residents in rural areas. Journal of Korean institute of Rural Architecture 14(3):9-16 (In Korean).

Chung, C. J and K. W. Kim. 1997. The theory of agricultural implement. Publishing Dept of Seoul National University. p. 12.

Gruber, S and W. Claupein. 2009. Effect of tillage intensity on weed infestation in organic farming. Soil Till. Res.
105:104-111.

Huang, W., F. Xu, J. Ge and C. Zhang. 2012. Simulated analysis of a wheeled tractor on soft soil based on Recurdyn. Springer's computer and computing technologies in agriculture V. IFIP advances in information and communication technology 370:333-342.

Hwang, J. B., S. T. Park, S. B. Song and B. C. Lee. 2007. Variation of weed occurrence and rice yield by using the cultivation weeder for three years in paddy rice. Korean Journal of Weed Science 27(4):334-340 (In Korea, with English abstract).

Kang, H. J. 2011. Analysis of factors affecting the off-farm Labor hours of Korean married women farmers. Journal of Women and Economics 8(2):1-28 (In Korean).

Kim, B., S. Y. Shin, H. K. Kim and Y. Y. Kim. 2013. A survey on the using state of agricultural machinery and mechanized rate. In: Proceedings of the KSAM\&KSBEC 2013 Spring Conference, pp. 137-138 (In Korean).

Kim, C. S and K. D. Kim. 2007. Development of a 2-row type band furrow tiller for a walking cultivator. Journal of Biosystems Engineering 32(4):223-229 (In Korean, with English abstract).

Kim, S., I. B. Im, J. G. Kang, J. D. Kim and G. I. Lee. 2006. Effect of cultivating weeder on tuber formation and shoot growth of elocharis kuroguwai in rice field. Korea Journal of Weed Science 26(3):303-308 (In Korean, with English abstract).

Kim, S., I. B. Im, S. H. Ahn, X. H. An and J. D. Kim. 2008. Weeding effect and rice yield by methods of weed management in rice production by organic farming with rice bran. Korean Journal of Weed Science 28(1):42-42 (In Korean).

Kim, Y. H., S. M. Kang, A. L. Kahn, J. H. Lee and I. J. Lee. 2011. Aspect of weed occureency by methods of weed control in rice field. Korea Journal of Weed Science 31(1):89-95 (In Korean, with English abstract).

Lee, K. S., S. H. Park, W. Y. Park and C. S. Lee. 2003. Strip tillage characteristics of rotary tiller blades for use in a dryland direct rice seeder. Soil. Till. Res. 71:25-32.

Lee, G. I., J. G. Won, S. W. Kim, C. S. Lee, S. N. Yoo, S. J. Hwang, H. H. Kim and D. E. Kim. 2007. The Korean Society of the Agricultural machinery. In: Proceedings of the KSAM '96 Conference 12(2), pp. 80-84 (In Korean, with English abstract).

Lee, S. G., H. G. Choi, C. T. Chung and J. Y. Pyon. 2010. Weed control and rice yield as affected by application timing of cultivator in rice bran treated paddy field. 
In: Proceedings of the KWSW'2010 Spring Conference 30(1), pp. 57-59 (In Korean).

Lim, K. H., S. G. Kim, D. L. Kim, Y. W. Seo, S. K. Yang, Y. S. Kim, H. J. Kim and J. G. Kim. 2009. The Effects of mulching materials and weed control methods on growth and weed occurrence of pesticide-free kale (Brassica oleracea L. var. acephala). Korean Journal of Organic Agriculture 17(4):501-517 (In Korean, with English abstract).

Lim, S. T., I. Y. Lee, J. R. Cho, B. C. Moon and J. E. Park. 2002. A possible weed management strategy using the cultivating weeder in rice paddy field. Korean Journal of Weed Science 22(3):259-265 (In Korean, with English abstract).

MA, S and S. Joachim. 2006. Review of history and recent development of organic farming worldwide. Agricultural Sciences in China. 5(3):169-178.

MFAFF. 2012. 2012 Food, Agriculture, Forestry and Fisheries Major Statistic. Ministry for Food, Agriculture, Forestry and Fisheries. 11-1541000-000314-10 (In Korean).

Nakamoto, T., J. Yamagishi and F. Miura. 2006. Effect of reduced tillage on weeds and soil organisms in winter wheat and summer maize cropping on Humic Andosols in Central Japan. Soil Till. Res. 85:94-106.

Ock, H. S and J. Y. Pyon. 2011. Trend and perspective of weed control techniques in organic farming. Korean Journal of Weed Science 31(1):8-23 (In Korean, with
English abstract).

RDA. 2008. The evaluation method of powered cultivating implement. Rural Development Administration. NAAS 2008-10-28.

Roh, S. W and J. Y. Pyon. 2004. Control of weeds in ginseng gardens by herbicides and mulching practices. Korean Journal of Weed Science 24(1):14-20 (In Korean, with English abstract).

Sohn, S. M. 2002. Situation of korean organic farming and its education and research in the future. Korean journal of organic agriculture 10(2):67-83 (In Korean, with English abstract).

Xie, X., Q. Sun, X. Yu and R. Du. 2011. Research on Coordinated Simulation of Medical Robot Arm Based on Simulink and RecurDyn. Applied Mechanics and Materials. 58-60 (2011):1300-1305.

Wang, Y. S., L. Z. Ge, P. C. Xie and Y. X. Gai. 2011. Dynamic simulation and gravity balancing optimization of spot welding robot based on Recurdyn. In: Proceedings of 2011 IEEE International conference on Mechatronics and automation, pp. 1905-1910

Won, J. G., D. J. Ahn, S. J. Kim, S. D. Park and C. D. Choi. 2008. Weed control by weeder machine in transplanted rice paddy field for mechanical weed control. Korean Journal of Weed Science 28(1):1-7 (In Korean, with English abstract). 